\title{
Shortest-Way: An Improved Empirical Transition Method for Signal Coordination
}

\author{
Mingming Zheng, ${ }^{1}$ Hongfeng Xu, ${ }^{2}$ Kun Zhang, ${ }^{2}$ and Ronghan Yao ${ }^{2}$ \\ ${ }^{1}$ School of Traffic and Transportation Engineering, Dalian Jiaotong University, Dalian, Liaoning 116028, China \\ ${ }^{2}$ School of Transportation and Logistics, Dalian University of Technology, Dalian, Liaoning 116024, China \\ Correspondence should be addressed to Hongfeng Xu; hfxu@dlut.edu.cn
}

Received 18 October 2016; Accepted 7 February 2017; Published 20 March 2017

Academic Editor: Yue Liu

Copyright (C) 2017 Mingming Zheng et al. This is an open access article distributed under the Creative Commons Attribution License, which permits unrestricted use, distribution, and reproduction in any medium, provided the original work is properly cited.

Four fundamental insights into transition methods are provided from the perspective of traffic engineers. An improved empirical transition method (i.e., Shortest-way) is developed with the goal of reducing the time spent on offset correction and the offset deviations of the coordinated phases during the transition period. Shortest-way operates stepwise and can be activated to correct offset at the scheduled time to switch plans. The maximum amount of adjustment that can be made to a transition cycle length is calculated based on the timing parameters of active phases in the old and new plans. The problem of cycle length distribution is formulated as a nonlinear integer programming problem, aiming at minimizing the sum of the squares of the intersection offset deviations of all the transition cycles. The portion of the cycle length that can be allocated to each phase in a transition cycle is calculated based on its splits in the old and new plans and its potential contribution to the maximum amount of adjustment to the cycle length. The numerical experimental results proved the potential advantage of Shortest-way over CORSIM Shortway and justified the necessity for managing the time to switch plans at the intersection level.

\section{Introduction}

Signal coordination requires that cycle length, splits, and offsets be defined to generate signal plans for intersections along an arterial. Changes in demand patterns dictate the need for switching signal plans from one another. If the old and new plans have different cycle lengths or offsets, the signal controller at an intersection will spend a period of time on correcting offsets by using a transition method before the new plan can be started.

Plan transition is an important engineering issue of signal coordination exercises. The existing transition methods can be categorized as empirical ones and theoretical ones. The prevailing empirical methods (i.e., Dwell, Max Dwell, Add, Subtract, and Shortway) have been widely used by signal controller vendors and practitioners [1-6]. Beginning at the end of the cycle where the scheduled time to switch plans is present, offset correction will be completed in a maximum of three to five cycles. A limited amount of adjustment is made to the cycle length and splits for all the phases in a stepwise and deterministic fashion. The key advantage of these methods is their low cost and simplicity in generating transition plans; that is, transition plans can be generated based on no more information than the timing parameters in old and new plans. There is a large body of evidence showing that Shortway (also sometimes called Bestway, Fastway, or Smooth) performs the best under most of the scenarios. The theoretical methods have been proposed by researchers for some years but were not found to be used in practice [7-10]. Of greatest concern to these methods is to optimize intersection performance (e.g., vehicle delay and vehicle emission) when transitioning plans. Sophisticated optimization models with real-time traffic volumes as independent variables are established to jointly determine the number of cycles, the cycle lengths, and the splits for all the phases during the transition period. A large amount of funding and effort for collecting traffic count data may be the primary reason that hinders the theoretical methods from being implemented in the field. Regardless of 
the complexity of a transition method, there is a potential for plan transition to lead to serious disruptions of traffic flow and long-lasting effects $[4,11]$.

Transition methods play a supporting role in exercising signal coordination and have been a subject of relatively little research within the scope of coordinated signal timing. In recent years, some research efforts on the theoretical methods have merited special attention [8-10]. From the perspective of traffic engineers, there are four fundamental insights into transition methods. First, changes to signal plans that are too frequent can be a detriment because the arterial never achieves signal coordination long enough to meet the desired operational objective. It is a common practice to remain in a signal plan for at least 30 minutes [12]. It is the case that the cycle length will be lengthened or shortened during the transition period. Typically, to ensure sufficient capacity for an intersection, a high-demand plan is implemented before the onset of the high-demand period, and a low-demand plan is implemented after the onset of the low-demand period. Quality signal plans and appropriate times to switch plans far outweigh a transition method in affecting the systemwide performance of an arterial. Second, transition method is independently executed by each signal controller without regard for the state of adjacent signal controllers. Offset deviation and the resulting poor quality of progression are common problems facing transition plans. The goal of reducing the cycle-by-cycle change in the offset may be unattainable due to big difference between the offsets in the old and new plans or be attainable at the expense of an excessive amount of time spent on offset correction. Third, the duration of transition period varies from a case to another from a few seconds to a few minutes. But performance measures are required to be evaluated over time periods of a minimum of 15 minutes [1216]. It is very difficult to distinguish and capture the transient impact of transition method on the performance measures. In a general sense, the time spent on offset correction and the offset deviations of the coordinated phases during the transition period should be the first focus when assessing the effectiveness of transition methods. Fourth, there is a long way to go before the costs and benefits of using the theoretical methods can be fully understood outside laboratory environment. The empirical methods, however, have been proven to be costeffective in the long-term engineering practice. Improvements in the empirical methods are required for practical purposes and will be more likely to gain acceptance and support from signal controller vendors and practitioners.

In this study, an improved empirical transition method (i.e., Shortest-way) is developed for pretimed or actuated coordinated signal systems. Technically, Shortest-way differs from the prevailing empirical methods in three aspects. First, the signal controller can shift the sync reference points and start correcting the offset at the scheduled time to switch plans. Second, the cycles during the transition period are unequally lengthened or shortened to optimize intersection offset deviations. Third, the amount of time added to or subtracted from each phase in a transition cycle is based on its potential contribution to the maximum amount of adjustment to the cycle length.
The remainder of this paper is organized as follows. The key techniques of Shortest-way are presented in Section 2. The numerical experiments are conducted in Section 3. Conclusions and future studies are provided in Section 4.

\section{Key Techniques}

Sync reference points are the points on the master clock to which each signal controller is referenced in order to establish an offset between coordinated phases. An offset is the time from the sync reference point to the start of green of a specific coordinated phase. An intersection offset is the time that elapses between the sync reference point and the start of green of the first phase in the sequence. From an arterial perspective, it is convenient to develop transition methods by using the concept of intersection offset. Figure 1 illustrates the relationship between the phase-specific offsets and intersection offset. A signal plan or a cycle can be regarded as being started as soon as the intersection offset is achieved.

Shortest-way can be activated at the scheduled times to switch plans to correct the intersection offset. There are five main steps that present the working procedure of Shortestway.

Step 1. Shift the sync reference points and locate the candidate start points of the new plan.

Step 2. Calculate the minimum and maximum cycle lengths during the transition period.

Step 3. Determine the actual start point of the new plan, the duration of transition period, and the number of transition cycles.

Step 4. Calculate the cycle length for each transition cycle.

Step 5. Calculate the portion of the cycle length that can be allocated to each phase in a transition cycle.

The key techniques of Shortest-way are presented for a typical four-leg intersection, as shown in Figure 2. Leftturn movements are protected and right-turn movements are permitted on all the approaches. There are a total of eight vehicle phases and four pedestrian phases. The right of way is assigned to the major street phases, followed by the minor street phases. Lead-lead left-turn sequence is applied on the major and minor streets. Pedestrian phases run concurrently with their adjacent through vehicle phases. For simplicity of presentation, assume that the minimum green times of the through vehicle phases are sufficient to accommodate the pedestrian timing requirements. None of the pedestrian intervals are discussed in the following.

2.1. Sync Reference Points. Figure 3 illustrates the sync reference points of a coordinated signal system. The master clock is referenced to a real-time clock and the variables in the boxes will be assigned with the times of day. The last sync reference point of the old plan $\left(\mathrm{SR}_{m}\right)$ is next to the left of the scheduled time to switch plans (STW), followed by the 


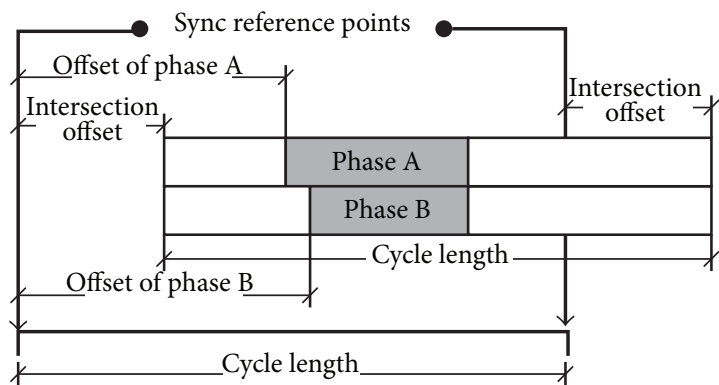

Splits for coordinated phases

Splits for noncoordinated phases

(a) Intersection offset $<$ phase-specific offsets

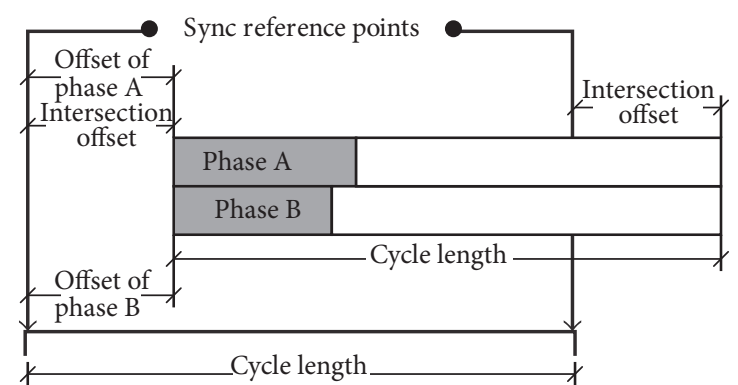

Splits for coordinated phases

Splits for noncoordinated phases

(b) Intersection offset $=$ phase-specific offsets

FIGURE 1: Relationship between the phase-specific offsets and intersection offset.
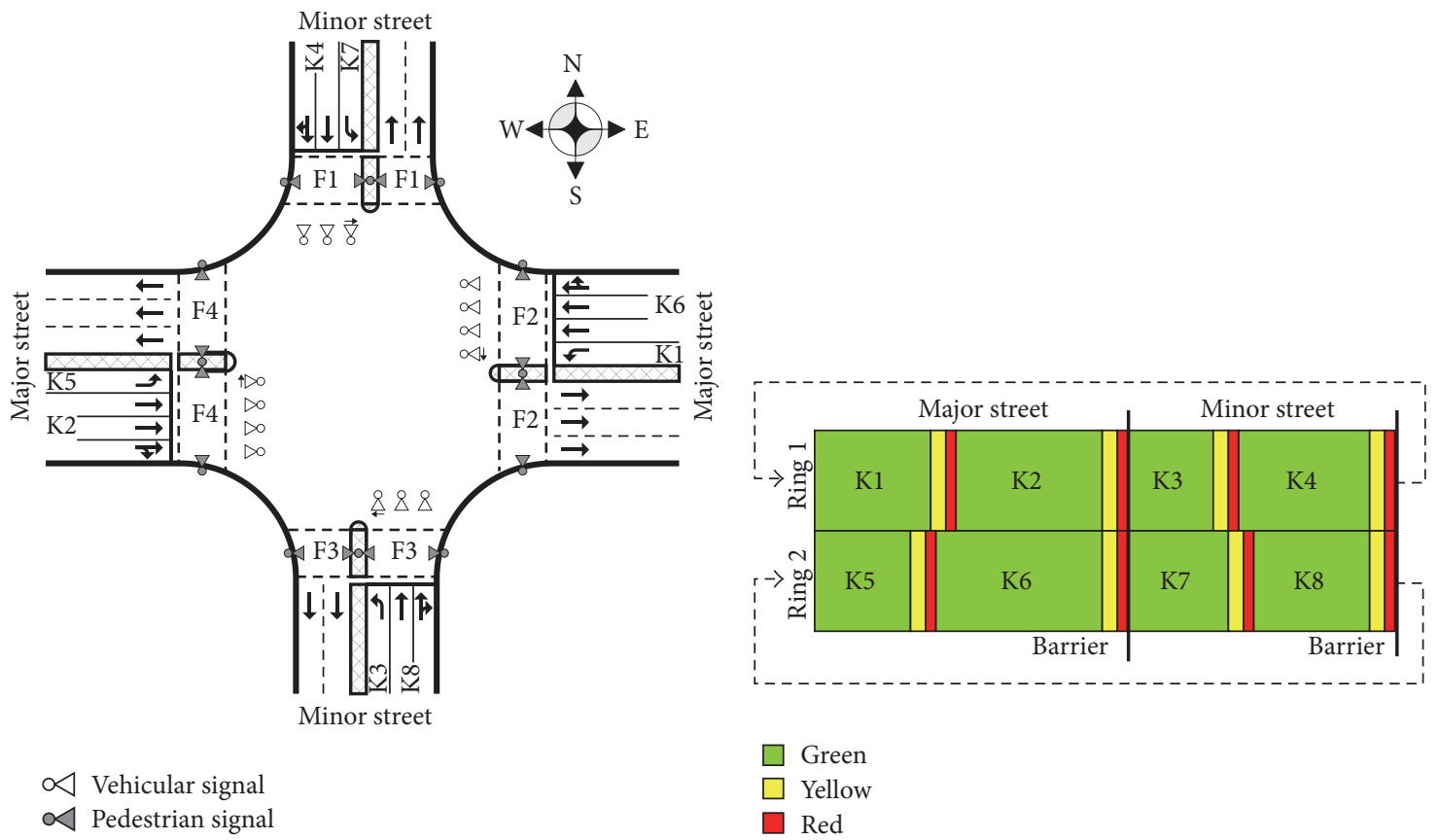

$\propto$ Vehicular signal

$\propto$ Pedestrian signal

(b) Ring-and-barrier diagram showing the lead-lead left-turn sequence

FIGURE 2: Intersection for presenting the key techniques of Shortest-way.

first sync reference point of the new plan $\left(\mathrm{SR}_{m+1}\right)$. The time interval between two adjacent sync reference points is as long as the cycle length of the old or new plan $\left(C_{\text {old }}\right.$ or $\left.C_{\text {new }}\right)$.

The cycle where STW is present serves as the first transition cycle. The start point of transition period (STP) is influenced by the location of STW. The value of STP is equal to the last point where the intersection offset of the old plan $\left(\mathrm{O}_{\mathrm{old}}\right)$ is achieved, given by

\section{STP}

$$
= \begin{cases}\mathrm{SR}_{m-1}+\mathrm{O}_{\mathrm{old}}, & \text { if } \mathrm{SR}_{m} \leq \mathrm{STW}<\mathrm{SR}_{m}+\mathrm{O}_{\mathrm{old}} \\ \mathrm{SR}_{m}+O_{\mathrm{old}}, & \text { if } \mathrm{SR}_{m}+O_{\mathrm{old}} \leq \mathrm{STW}<\mathrm{SR}_{m+1}\end{cases}
$$

As shown in Figure 3, based on the sync reference points of the new plan (i.e., $\mathrm{SR}_{m+1}, \mathrm{SR}_{m+2}, \ldots$ ), the intersection offset of the new plan $\left(\mathrm{O}_{\text {new }}\right)$ can be achieved at multiple points. The earlier the new plan is started, the shorter the duration of transition period is. The $n$th candidate start point of the new plan $\left(\mathrm{CSNP}_{n}\right)$ is given by

$$
\mathrm{CSNP}_{n}=\mathrm{SR}_{m+n}+\mathrm{O}_{\text {new }}
$$

where $\mathrm{SR}_{m+n}$ is the $n$th sync reference point of the new plan.

(1) 2.2. Minimum and Maximum Transition Cycle Lengths. In the first transition cycle, the signal controller will remain in the old plan until there exists an opportunity to adjust 


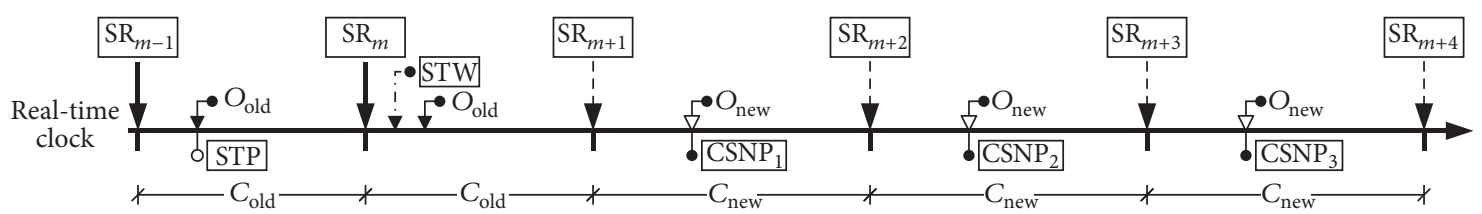

(a) Scenario 1: $\mathrm{SR}_{m} \leq \mathrm{STW}<\mathrm{SR}_{m}+\mathrm{O}_{\text {old }}$

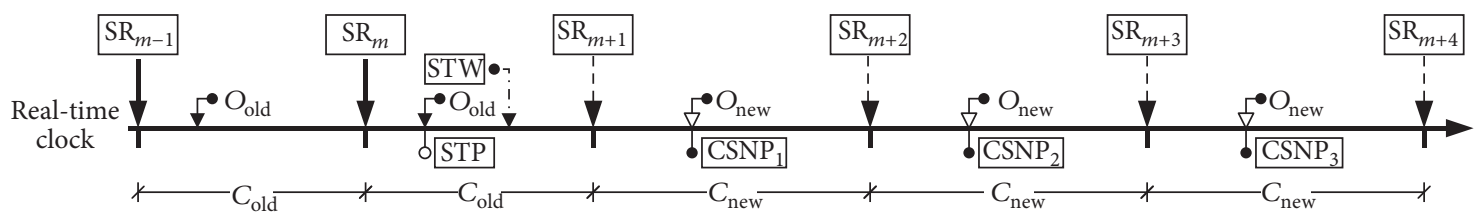

(b) Scenario 2: $\mathrm{SR}_{m}+\mathrm{O}_{\text {old }} \leq \mathrm{STW}<\mathrm{SR}_{m+1}$

FIGURE 3: Sync reference points illustrated.

TABLE 1: Time window definition illustrated.

\begin{tabular}{|c|c|c|c|}
\hline Time window & Start point & End point & Active phases \\
\hline TW1 & STP & $\mathrm{STP}+\min \left\{\begin{array}{l}G \min _{\mathrm{old}}^{\mathrm{K} 1} \\
G \min _{\mathrm{old}}^{\mathrm{K} 5}\end{array}\right.$ & $\mathrm{K} 1, \mathrm{~K} 2, \mathrm{~K} 3, \mathrm{~K} 4, \mathrm{~K} 5, \mathrm{~K} 6, \mathrm{~K} 7$, and $\mathrm{K} 8$ \\
\hline TW2 & $\mathrm{STP}+\min \left\{\begin{array}{l}G \min _{\mathrm{old}}^{\mathrm{K} 1} \\
G \min _{\mathrm{old}}^{\mathrm{K} 5}\end{array}\right.$ & $\mathrm{STP}+\max \left\{\begin{array}{l}S_{\mathrm{old}}^{\mathrm{K} 1}+G \min _{\mathrm{old}}^{\mathrm{K} 2} \\
S_{\mathrm{old}}^{\mathrm{K} 5}+G \min _{\mathrm{old}}^{\mathrm{K} 6}\end{array}\right.$ & $\mathrm{K} 2, \mathrm{~K} 3, \mathrm{~K} 4, \mathrm{~K} 6, \mathrm{~K} 7$, and $\mathrm{K} 8$ \\
\hline TW3 & $\mathrm{STP}+\max \left\{\begin{array}{l}S_{\mathrm{old}}^{\mathrm{K} 1}+G \min _{\mathrm{old}}^{\mathrm{K} 2} \\
S_{\mathrm{old}}^{\mathrm{K} 5}+G \min _{\mathrm{old}}^{\mathrm{K} 6}\end{array}\right.$ & $\mathrm{STP}+C_{\mathrm{old}}^{\mathrm{ma}}+\min \left\{\begin{array}{l}G \min _{\mathrm{old}}^{\mathrm{K} 3} \\
G \min _{\mathrm{old}}^{\mathrm{K} 7}\end{array}\right.$ & $\mathrm{K} 3, \mathrm{~K} 4, \mathrm{~K} 7$, and $\mathrm{K} 8$ \\
\hline TW4 & $\mathrm{STP}+C_{\mathrm{old}}^{\mathrm{ma}}+\min \left\{\begin{array}{l}G \min _{\mathrm{old}}^{\mathrm{K} 3} \\
G \min _{\mathrm{old}}^{\mathrm{K} 7}\end{array}\right.$ & $\mathrm{STP}+C_{\mathrm{old}}^{\mathrm{ma}}+\max \left\{\begin{array}{l}S_{\mathrm{old}}^{\mathrm{K} 3}+G \min _{\mathrm{old}}^{\mathrm{K} 4} \\
S_{\mathrm{old}}^{\mathrm{K} 7}+G \min _{\mathrm{old}}^{\mathrm{K} 8}\end{array}\right.$ & $\mathrm{K} 4$ and $\mathrm{K} 8$ \\
\hline TW5 & $\mathrm{STP}+C_{\mathrm{old}}^{\mathrm{ma}}+\max \left\{\begin{array}{l}S_{\mathrm{old}}^{\mathrm{K} 3}+G \min _{\mathrm{old}}^{\mathrm{K} 4} \\
S_{\text {old }}^{\mathrm{K} 7}+G \min _{\mathrm{old}}^{\mathrm{K} 8}\end{array}\right.$ & $\mathrm{STP}+C_{\text {old }}$ & None \\
\hline
\end{tabular}

$G \min _{\text {old }}^{\mathrm{Ki}}$ is the minimum green time of phase $\mathrm{K} i$ in the old plan $(i=1,2, \ldots, 8) ; S_{\text {old }}^{\mathrm{Ki}}$ is the split for phase $\mathrm{K} i$ in the old plan; and $C_{\text {old }}^{\mathrm{ma}}$ is the portion of the cycle length allocated to the major street phases in the old plan.

the splits for some phases. The time interval between STP and $\left(\mathrm{STP}+\mathrm{C}_{\mathrm{old}}\right)$ can be divided into five time windows (i.e., TW1, TW2,.., TW5), as shown in Table 1. The key information for defining the time windows includes the phase sequence used and the timing parameters of the old plan. The active phases that are capable of adjusting their splits in the first transition cycle can be identified according to the time window where STW is present. The adjustment of the splits for the active phases results in a lengthening or shortening cycle length. The more the number of active phases, the larger the amount of adjustment that can be made to the cycle length.

The second and subsequent transition cycles, if they exist, are obtained by lengthening or shortening the cycle length of the new plan within a specified range. All the phases in the sequence are the active phases being involved in the cycle length adjustment.

Specifically, the minimum green time that is defined for each phase in the old and new plans limits the maximum amount of time subtracted from the split for the phase. Under the constraint of pedestrian timing requirements, a minimum green time that is relatively large can be assigned to a coordinated phase or an uncoordinated phase with insufficient capacity, while a minimum green time that is relatively small can be assigned to an uncoordinated phase with sufficient capacity.

The minimum and maximum cycle lengths of the $x$ th transition cycle $\left[C \min (x)_{t}\right.$ and $\left.C \max (x)_{t}\right]$ are given by

$$
\begin{aligned}
& C \min (x)_{t} \\
& =\max \left\{\begin{array}{l}
S \min (x)_{t}^{\mathrm{K} 1}+S \min (x)_{t}^{\mathrm{K} 2} \\
S \min (x)_{t}^{\mathrm{K} 5}+S \min (x)_{t}^{\mathrm{K} 6}
\end{array}\right. \\
& +\max \left\{\begin{array}{l}
S \min (x)_{t}^{\mathrm{K} 3}+S \min (x)_{t}^{\mathrm{K} 4} \\
S \min (x)_{t}^{\mathrm{K} 7}+S \min (x)_{t}^{\mathrm{K} 8},
\end{array}\right.
\end{aligned}
$$




$$
\begin{aligned}
& C \max (x)_{t} \\
& =\min \left\{\begin{array}{l}
S \max (x)_{t}^{\mathrm{K} 1}+S \max (x)_{t}^{\mathrm{K} 2} \\
S \max (x)_{t}^{\mathrm{K} 5}+S \max (x)_{t}^{\mathrm{K} 6}
\end{array}\right. \\
& +\min \left\{\begin{array}{l}
S \max (x)_{t}^{\mathrm{K} 3}+S \max (x)_{t}^{\mathrm{K} 4} \\
S \max (x)_{t}^{\mathrm{K} 7}+S \max (x)_{t}^{\mathrm{K} 8},
\end{array}\right. \\
& S \min (x)_{t}^{\mathrm{K} i} \\
& = \begin{cases}G \min _{\text {old }}^{\mathrm{K} i}+Y^{\mathrm{K} i}+R^{\mathrm{K} i}, & \text { if }(x=1),\left(A_{t}^{\mathrm{K} i}=1\right) \\
S_{\text {old }}^{\mathrm{K} i}, & \text { if }(x=1),\left(A_{t}^{\mathrm{K} i}=0\right) \\
G \min _{\text {new }}^{\mathrm{K} i}+Y^{\mathrm{K} i}+R^{\mathrm{K} i}, & \text { if } x>1,\end{cases}
\end{aligned}
$$

$$
\begin{aligned}
S & \max (x)_{t}^{\mathrm{K} i} \\
= & \begin{cases}\left\lfloor S_{\text {old }}^{\mathrm{K} i} *\left(1+f_{+}\right)\right], & \text {if }(x=1),\left(A_{\mathrm{t}}^{\mathrm{K} i}=1\right) \\
S_{\mathrm{old}}^{\mathrm{K} i}, & \text { if }(x=1),\left(A_{\mathrm{t}}^{\mathrm{K} i}=0\right) \\
\left.\mid S_{\text {new }}^{\mathrm{K} i} *\left(1+f_{+}\right)\right], & \text {if } x>1,\end{cases}
\end{aligned}
$$

where $S \min (x)_{t}^{\mathrm{Ki}}$ and $S \max (x)_{t}^{\mathrm{K} i}$ are the minimum and maximum splits for phase $\mathrm{K} i$ in the $x$ th transition cycle ( $i=$ $1,2, \ldots, 8) ; G \min _{\text {new }}^{\mathrm{Ki}}$ is the minimum green time of phase $\mathrm{K} i$ in the new plan; $Y^{\mathrm{K} i}$ and $R^{\mathrm{K} i}$ are the yellow change interval and red clearance interval of phase $\mathrm{K} i ; A_{t}^{\mathrm{K} i}=1$ if phase $\mathrm{K} i$ is the active phase in the first transition cycle and $A_{t}^{\mathrm{K} i}=0$ otherwise; $f_{+}$is the maximum percentage that the split for a phase in the old or new plan can be lengthened during the transition period; $S_{\text {new }}^{\mathrm{K} i}$ is the split for phase Ki in the new plan; and $L \backslash$ is the round-to-the-nearest-integer operator.

2.3. Duration of Transition Period. Assuming that there is a total of $X$ transition cycles $(X=1,2, \ldots)$, the minimum and maximum durations of transition period $\left(T \min _{t}\right.$ and $\left.T \max _{t}\right)$ can be expressed by

$$
\begin{aligned}
\operatorname{Tmin}_{t} & =\sum_{x=1}^{X} C \min (x)_{t}, \\
T \max _{t} & =\sum_{x=1}^{X} C \max (x)_{t} .
\end{aligned}
$$

As shown in Figure 4, the actual start point of the new plan (SNP), the duration of transition period $\left(T_{t}\right)$, and the number of transition cycles $(X)$ can be identified by analyzing the relationship among $\mathrm{CSNP}_{n}, T \min _{t}$, and $T \max _{t}$. It should be noted that there is no constraint placed on the maximum

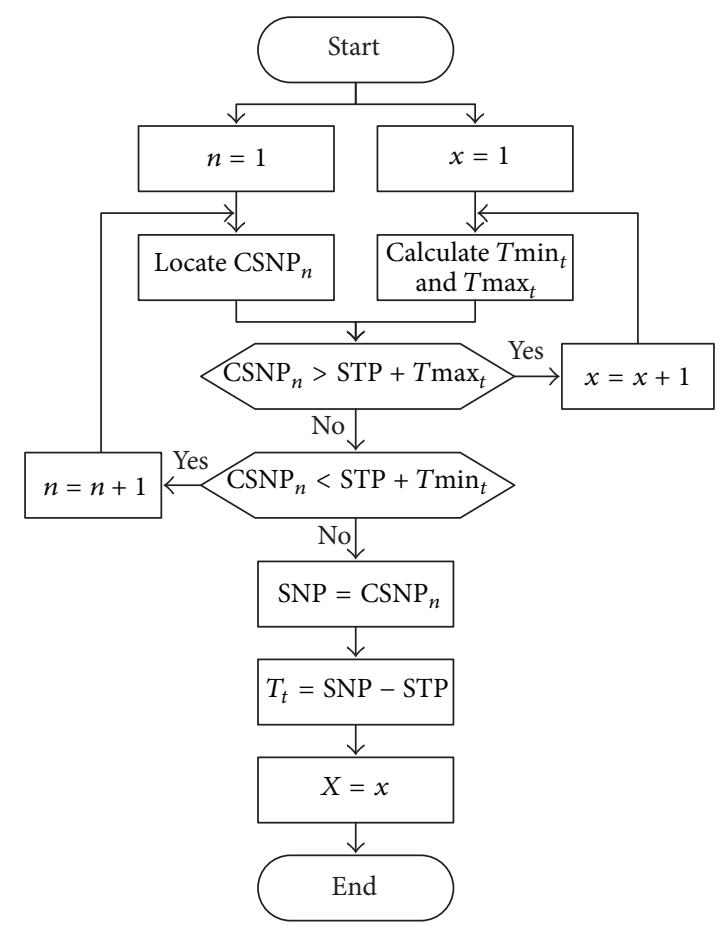

FIgURE 4: SNP, $T_{t}$, and $X$ determination process.

number of transition cycles because this may override the minimum and maximum transition cycle lengths for the worst case scenarios.

2.4. Cycle Length Distribution. One of the consequences of adjusting the cycle length and splits during the transition period is the potential for the coordinated phases to begin earlier or later than expected. The signal controllers at adjacent intersections execute the transition method in isolation, resulting in early or late return to the coordinated phases which is difficult to manage along an arterial. For the scenarios in which a large amount of adjustment needs be made to the cycle length, there is no immediate and effective alternative to prevent poor quality of progression without increasing the duration of transition period. One technique that can be used to allow for the coordinated relationship between intersections is to minimize the intersection offset deviations during the transition period.

Knowing STP and $X$, the actual start point of the $x$ th transition cycle $\left[\operatorname{ASTC}(x)_{t}\right]$ is given by

$$
\operatorname{ASTC}(x)_{t}= \begin{cases}\text { STP, } & \text { if } x=1 \\ \text { STP }+\sum_{x=2}^{X} C(x-1)_{t}, & \text { if } x>1,\end{cases}
$$

where $C(x)_{t}$ is the cycle length of the $x$ th transition cycle.

Beginning from the sync reference point next to the left of STP, the optimal start point of the $x$ th transition cycle $\left[\operatorname{OSTC}(x)_{t}\right]$ is the point where the intersection offset of the old or new plan $\left(O_{\text {old }}\right.$ or $\left.O_{\text {new }}\right)$ is achieved, given by 


$$
\operatorname{OSTC}(x)_{t}= \begin{cases}\mathrm{SR}_{m+x-2}+\mathrm{O}_{\mathrm{old}}, & \text { if }\left(\mathrm{SR}_{m} \leq \mathrm{STW}<\mathrm{SR}_{m}+\mathrm{O}_{\mathrm{old}}\right),(x=1 \text { or } 2) \\ \mathrm{SR}_{m+x-2}+\mathrm{O}_{\text {new }}, & \text { if }\left(\mathrm{SR}_{m} \leq \mathrm{STW}<\mathrm{SR}_{m}+\mathrm{O}_{\mathrm{old}}\right),(x>2) \\ \mathrm{SR}_{m+x-1}+O_{\text {old }}, & \text { if }\left(\mathrm{SR}_{m}+\mathrm{O}_{\text {old }} \leq \mathrm{STW}<\mathrm{SR}_{m+1}\right),(x=1) \\ \mathrm{SR}_{m+x-1}+O_{\text {new }}, & \text { if }\left(\mathrm{SR}_{m}+O_{\text {old }} \leq \mathrm{STW}<\mathrm{SR}_{m+1}\right),(x>1) .\end{cases}
$$

The intersection offset deviation of the $x$ th transition cycle $\left[\mathrm{OD}(x)_{t}\right]$ can be expressed by

$$
\operatorname{OD}(x)_{t}=\operatorname{ASTC}(x)_{t}-\operatorname{OSTC}(x)_{t}
$$

The value of $\operatorname{OD}(x)_{t}$ may be positive or negative and should be squared when being used to define an objective function. In order to distribute $T_{t}$ to $X$ transition cycles, a nonlinear integer programming model is established to minimize the sum of the squares of the intersection offset deviations of all the transition cycles, given by

$$
\begin{array}{ll}
\min & \sum_{x=1}^{X}\left[\mathrm{OD}(x)_{t}\right]^{2} \\
\text { s.t. } & C \min (x)_{t} \leq C(x)_{t} \leq C \max (x)_{t}
\end{array}
$$

$$
\begin{aligned}
& \sum_{x=1}^{X} C(x)_{t}=T_{t} \\
& C(x)_{t}, x, X \text { are integers. }
\end{aligned}
$$

2.5. Split Distribution. The amount of adjustment to the cycle length during the transition period is distributed to the major street and minor street phases, based on their potential contributions to the maximum amount of adjustment to the cycle length. The portions of the cycle length that can be allocated to the major street and minor street phases in the $x$ th transition cycle $\left[C(x)_{t}^{\mathrm{ma}}\right.$ and $\left.C(x)_{t}^{\mathrm{mi}}\right]$ are given by

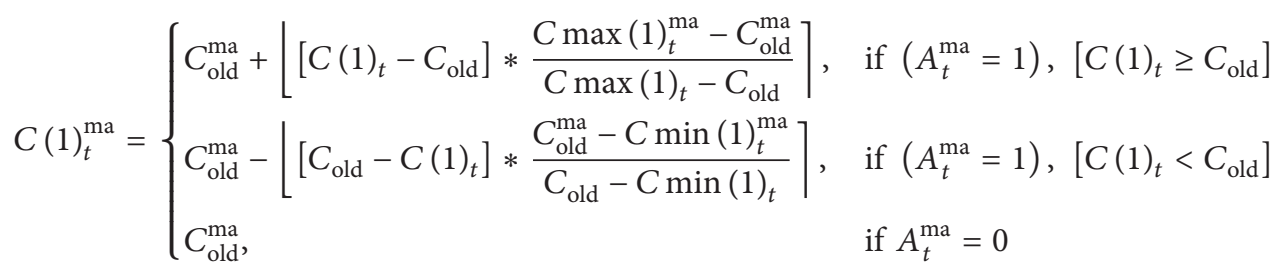

$$
\begin{aligned}
& C(x)_{t}^{\mathrm{ma}}= \begin{cases}C_{\text {new }}^{\mathrm{ma}}+\left\lfloor\left[C(x)_{t}-C_{\text {new }}\right] * \frac{C \max (x)_{t}^{\mathrm{ma}}-C_{\text {new }}^{\mathrm{ma}}}{C \max (x)_{t}-C_{\text {new }}}\right\rceil, & \text { if }(x>1), \quad\left[C(x)_{t} \geq C_{\text {new }}\right] \\
C_{\text {new }}^{\mathrm{ma}}-\left\lfloor\left[C_{\text {new }}-C(x)_{t}\right] * \frac{C_{\text {new }}^{\mathrm{ma}}-C \min (x)_{t}^{\mathrm{ma}}}{C_{\text {new }}-C \min (x)_{t}}\right\rfloor, & \text { if }(x>1),\left[C(x)_{t}<C_{\text {new }}\right]\end{cases} \\
& C(x)_{t}^{\mathrm{mi}}=C(x)_{t}-C(x)_{t}^{\mathrm{ma}} \\
& C \min (x)_{t}^{\mathrm{ma}}=\max \left\{\begin{array}{l}
S \min (x)_{t}^{\mathrm{K} 1}+S \min (x)_{t}^{\mathrm{K} 2} \\
S \min (x)_{t}^{\mathrm{K} 5}+S \min (x)_{t}^{\mathrm{K} 6}
\end{array}\right. \\
& C \max (x)_{t}^{\mathrm{ma}}=\min \left\{\begin{array}{l}
S \max (x)_{t}^{\mathrm{K} 1}+S \max (x)_{t}^{\mathrm{K} 2} \\
S \max (x)_{t}^{\mathrm{K} 5}+S \max (x)_{t}^{\mathrm{K} 6},
\end{array}\right.
\end{aligned}
$$

where $C \min (x)_{t}^{\mathrm{ma}}$ and $C \max (x)_{t}^{\mathrm{ma}}$ are the minimum and maximum portions of the cycle length that can be allocated to the major street phases in the $x$ th transition cycle; $C_{\text {new }}^{\text {ma }}$ is the portion of the cycle length allocated to the major street phases in the new plan; $A_{t}^{\mathrm{ma}}=1$ if there are major street active phases in the first transition cycle and $A_{t}^{\mathrm{ma}}=0$ otherwise; and \lfloor\rceil is the round-to-the-nearest-integer operator.

The amount of adjustment to the portion of the cycle length allocated to the major street or minor street phases during the transition period is further distributed to all the 
phases on the street, based on their potential contributions to the maximum amount of adjustment to the portion of the cycle length. The split for phase $\mathrm{K} i$ in the $x$ th transition cycle $\left[S(x)_{t}^{\mathrm{Ki}}\right]$ is given by

$$
\begin{aligned}
& S(1)_{t}^{\mathrm{K} 1}= \begin{cases}S_{\mathrm{old}}^{\mathrm{K} 1}+\left\lfloor\left[C(1)_{t}^{\mathrm{ma}}-C_{\mathrm{old}}^{\mathrm{ma}}\right] * \frac{S \max (1)_{t}^{\mathrm{K} 1}-S_{\mathrm{old}}^{\mathrm{K} 1}}{\sum_{i=1}^{2}\left[S \max (1)_{t}^{\mathrm{K} i}-S_{\text {old }}^{\mathrm{K} i}\right]}\right], & \text { if }\left(A_{t}^{\mathrm{K} 1}=1\right),\left[C(1)_{t} \geq C_{\mathrm{old}}\right] \\
S_{\mathrm{old}}^{\mathrm{K} 1}-\left\lfloor\left[C_{\mathrm{old}}^{\mathrm{ma}}-C(1)_{t}^{\mathrm{ma}}\right] * \frac{S_{\mathrm{old}}^{\mathrm{K} 1}-S \min (1)_{t}^{\mathrm{K} 1}}{\sum_{i=1}^{2}\left[S_{\text {old }}^{\mathrm{K} i}-S \min (1)_{t}^{\mathrm{K} i}\right]}\right], & \text { if }\left(A_{t}^{\mathrm{K} 1}=1\right),\left[C(1)_{t}<C_{\mathrm{old}}\right] \\
S_{\mathrm{old}}^{\mathrm{K} 1}, & \text { if } A_{t}^{\mathrm{K} 1}=0\end{cases}
\end{aligned}
$$

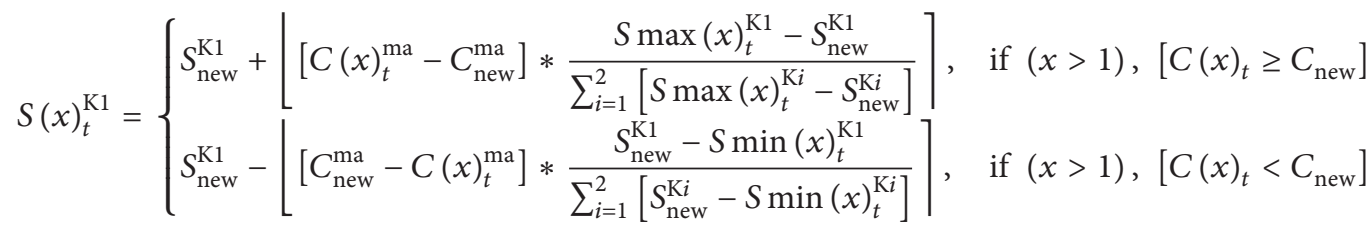

$$
\begin{aligned}
& S(x)_{t}^{\mathrm{K} 2}=C(x)_{t}^{\mathrm{ma}}-S(x)_{t}^{\mathrm{K} 1}
\end{aligned}
$$

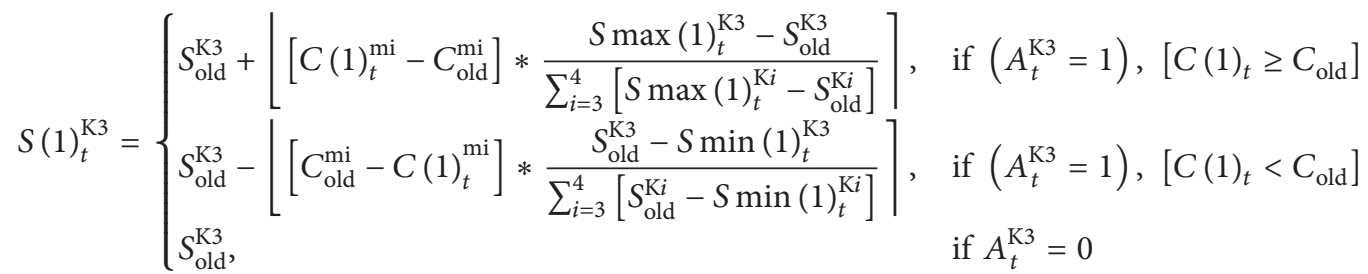

$$
\begin{aligned}
& S(x)_{t}^{\mathrm{K} 3}= \begin{cases}S_{\text {new }}^{\mathrm{K} 3}+\left\lfloor\left[C(x)_{t}^{\mathrm{mi}}-C_{\mathrm{new}}^{\mathrm{mi}}\right] * \frac{S \max (x)_{t}^{\mathrm{K} 3}-S_{\text {new }}^{\mathrm{K} 3}}{\sum_{i=3}^{4}\left[S \max (x)_{t}^{\mathrm{Ki}}-S_{\text {new }}^{\mathrm{Ki}}\right]}\right], & \text { if }(x>1), \quad\left[C(x)_{t} \geq C_{\mathrm{new}}\right] \\
S_{\text {new }}^{\mathrm{K} 3}-\left\lfloor\left[C_{\mathrm{new}}^{\mathrm{mi}}-C(x)_{t}^{\mathrm{mi}}\right] * \frac{S_{\text {new }}^{\mathrm{K} 3}-S \min (x)_{t}^{\mathrm{K} 3}}{\sum_{i=3}^{4}\left[S_{\text {new }}^{\mathrm{Ki}}-S \min (x)_{t}^{\mathrm{K} i}\right]}\right], & \text { if }(x>1),\left[C(x)_{t}<C_{\text {new }}\right]\end{cases} \\
& S(x)_{t}^{\mathrm{K} 4}=C(x)_{t}^{\mathrm{mi}}-S(x)_{t}^{\mathrm{K} 3} \\
& S(1)_{t}^{\mathrm{K} 5}= \begin{cases}S_{\text {old }}^{\mathrm{K} 5}+\left\lfloor\left[C(1)_{t}^{\mathrm{ma}}-C_{\mathrm{old}}^{\mathrm{ma}}\right] * \frac{S \max (1)_{t}^{\mathrm{K} 5}-S_{\text {old }}^{\mathrm{K} 5}}{\sum_{i=5}^{6}\left[S \max (1)_{t}^{\mathrm{K} i}-S_{\text {old }}^{\mathrm{K} i}\right]}\right], & \text { if }\left(A_{t}^{\mathrm{K} 5}=1\right), \quad\left[C(1)_{t} \geq C_{\text {old }}\right] \\
S_{\text {old }}^{\mathrm{K} 5}-\left\lfloor\left[C_{\mathrm{old}}^{\mathrm{ma}}-C(1)_{t}^{\mathrm{ma}}\right] * \frac{S_{\text {old }}^{\mathrm{K}}-S \min (1)_{t}^{\mathrm{K} 5}}{\sum_{i=5}^{6}\left[S_{\mathrm{old}}^{\mathrm{K} i}-S \min (1)_{t}^{\mathrm{K} i}\right]}\right], & \text { if }\left(A_{t}^{\mathrm{K} 5}=1\right), \quad\left[C(1)_{t}<C_{\text {old }}\right] \\
S_{\text {old }}^{\mathrm{K} 5}, & \text { if } A_{t}^{\mathrm{K} 5}=0\end{cases}
\end{aligned}
$$

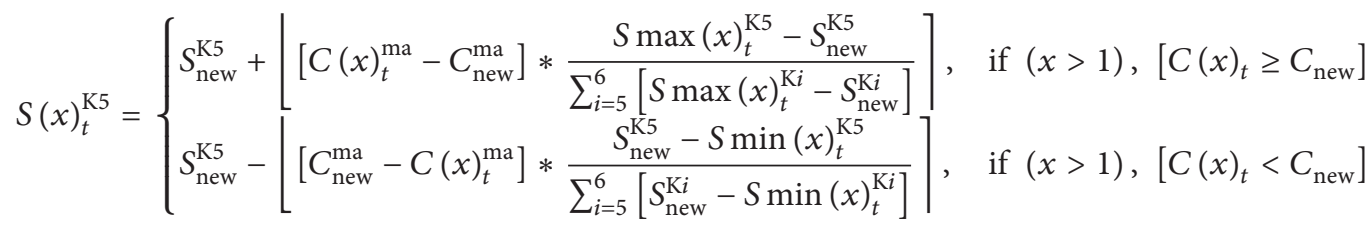

$$
\begin{aligned}
& S(x)_{t}^{\mathrm{K} 6}=C(x)_{t}^{\mathrm{ma}}-S(x)_{t}^{\mathrm{K} 5} \\
& S(1)_{t}^{\mathrm{K} 7}= \begin{cases}S_{\text {old }}^{\mathrm{K} 7}+\left\lfloor\left[C(1)_{t}^{\mathrm{mi}}-C_{\mathrm{old}}^{\mathrm{mi}}\right] * \frac{S \max (1)_{t}^{\mathrm{K} 7}-S_{\text {old }}^{\mathrm{K} 7}}{\sum_{i=7}^{8}\left[S \max (1)_{t}^{\mathrm{Ki}}-S_{\mathrm{old}}^{\mathrm{Ki}}\right]}\right], & \text { if }\left(A_{t}^{\mathrm{K} 7}=1\right), \quad\left[C(1)_{t} \geq C_{\mathrm{old}}\right] \\
S_{\text {old }}^{\mathrm{K} 7}-\left\lfloor\left[C_{\text {old }}^{\mathrm{mi}}-C(1)_{t}^{\mathrm{mi}}\right] * \frac{S_{\text {old }}^{\mathrm{K}}-S \min (1)_{t}^{\mathrm{K} 7}}{\sum_{i=7}^{8}\left[S_{\mathrm{old}}^{\mathrm{Ki}}-S \min (1)_{t}^{\mathrm{Ki}}\right]}\right], & \text { if }\left(A_{t}^{\mathrm{K} 7}=1\right), \quad\left[C(1)_{t}<C_{\mathrm{old}}\right] \\
S_{\text {old }}^{\mathrm{K} 7}, & \text { if } A_{t}^{\mathrm{K} 7}=0\end{cases}
\end{aligned}
$$




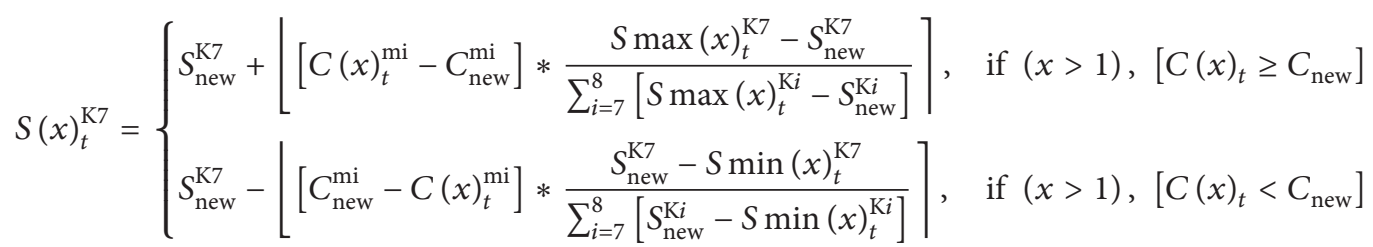

$$
\begin{aligned}
& S(x)_{t}^{\mathrm{K} 8}=C(x)_{t}^{\mathrm{mi}}-S(x)_{t}^{\mathrm{K} 7}
\end{aligned}
$$

where $C_{\text {old }}^{\mathrm{mi}}$ and $C_{\text {new }}^{\mathrm{mi}}$ are the portions of the cycle length allocated to the minor street phases in the old and new plans; and \lfloor\rceil is the round-to-the-nearest-integer operator.

\section{Numerical Experiments}

In view of the complex nature of the operating environment where transition methods are used, there are two types of in-house experiments (i.e., numerical experiments and simulation experiments) that can be conducted to assess the effectiveness of transition methods. Numerical experiments measure the static performance measures that are irrelevant to the operating environment. Simulation experiments measure the dynamic performance measures that vary with a variety of factors, such as simulation tool, simulation modeling, test bed arterial, traffic demands, signal plans, scheduled times to switch plans, and transition method.

In this section, a total of six numerical experiments were conducted at the typical intersection (see Figure 2(a)) to make a comparison of the static performance Shortest-way and one of the most representative and successful empirical methods, CORSIM Shortway [17].

3.1. Old and New Plans. Table 2 shows the old and new plans for the experiments. Phases K2 and K6 were the coordinated phases. There were three phase sequence options available on the major street: lead-lead left turn, lead-lag left turn, and lag-lag left turn. Lead-lead left-turn sequence was applied on the minor street. The signal controller switched from the pre-peak-period plans to the peak-period plans in experiments 1 to 3 and switched from the peak-period plans to the post-peak-period plans in experiments 4 to 6 . For each experiment, two scheduled times to switch plans (STW1 and STW2) were randomly selected between $\mathrm{SR}_{m}$ and $\mathrm{SR}_{m+1}$.

For Shortest-way, $f_{+}$was set to $20 \%$. For CORSIM Shortway, the splits for all the phases could be lengthened or shortened proportionally to their splits in the new plan with the maximum percentage of $+20 \%$ or $-17 \%$.

3.2. Results. Figure 5 shows the cycle lengths between $\mathrm{SR}_{m-3}$ and $\mathrm{SR}_{m+4}$. The plotted values varied from the cycle length of the old plan, via the ones during the transition period, to the one of the new plan. For the transition periods covering multiple cycles, there was a noticeable variation in the transition cycle lengths yielded by Shortest-way. This was saying that the nonlinear integer programming model had played an effective role in optimizing the intersection offset deviations when distributing the duration of transition period to each transition cycle. Shortest-way method completed offset correction in a maximum of four cycles (see experiment 2). The computational time for the signal controller to solve the nonlinear integer programming model could be negligible. By contrast, CORSIM Shortway, as expected, equally lengthened or shortened the cycle length of the new plan to obtain the transition cycle lengths.

The time spent on offset correction was calculated as follows: SNP - STW. As shown in Figure 6, Shortestway completed the offset correction no later than CORSIM Shortway, which meant that Shortest-way had a potential advantage over CORSIM Shortway in reducing the time spent on offset correction. Most of the transition periods lasted for a few minutes regardless of the transition method used. There seemed to be no better way to maintain the operational objective of an arterial than to avoid switching plans during the conditions when the intersections along the arterial needed to operate at maximum efficiency. It was noted that either STW1 or STW2 could lead to less time spent on offset correction. In order to mitigate the interruption of transition methods on the signal coordination along an arterial, it was viable to manage the time to switch plans at the intersection level.

The intersection offset deviation could be converted into the offset deviation of a coordinated phase according to the phase sequence used and the splits for the phases before the coordinated phase. Figure 7 shows the offset deviations of the coordinated phases (i.e., phases $\mathrm{K} 2$ and K6) relative to $\mathrm{SR}_{m-3}, \mathrm{SR}_{m-2}, \ldots$, and $\mathrm{SR}_{m+3}$, respectively. It was quite clear that the offset deviations yielded by Shortest-way were typically smaller than those yielded by CORSIM Shortway; that is, Shortest-way had a potential advantage over CORSIM Shortway in reducing the offset deviations of the coordinated phases during the transition period. This was the consequence of optimizing the intersection offset deviations and distributing the splits more fairly and equitably. Nevertheless, there still existed large offset deviations in some instances regardless of the transition method used. There seemed to be no better way to maintain the coordination relationships between intersections than to start the new plan as quickly as possible. Again, the phenomenon that either STW1 or STW2 could lead to smaller offset deviations further strengthened the necessity for managing the time to switch plans at the intersection level. 


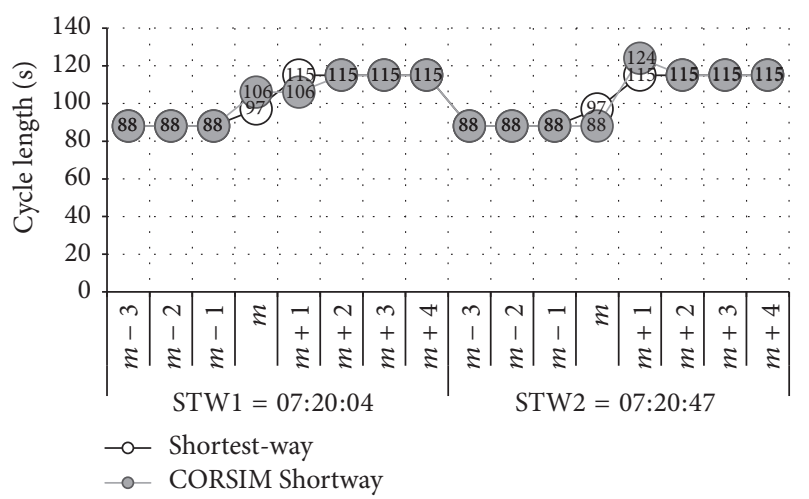

(a) Exp. $1\left(\mathrm{SR}_{m}=07: 20: 00 ; \mathrm{SR}_{m+1}=07: 21: 28\right)$

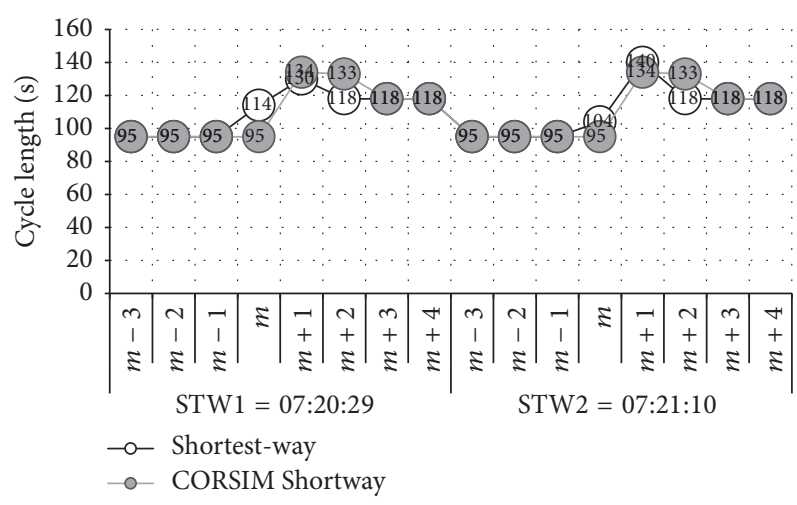

(c) $\operatorname{Exp} .3\left(\mathrm{SR}_{m}=07: 20: 00 ; \mathrm{SR}_{m+1}=07: 21: 35\right)$

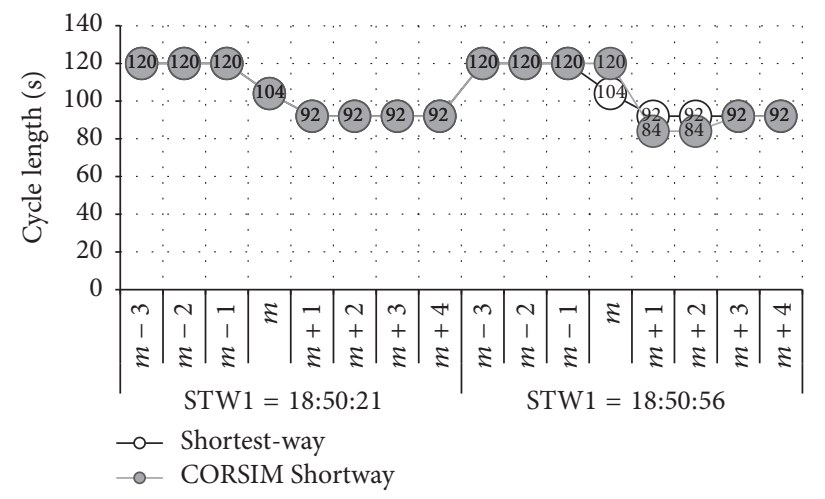

(e) $\operatorname{Exp} .5\left(\mathrm{SR}_{m}=18: 50: 00 ; \mathrm{SR}_{m+1}=18: 52: 00\right)$

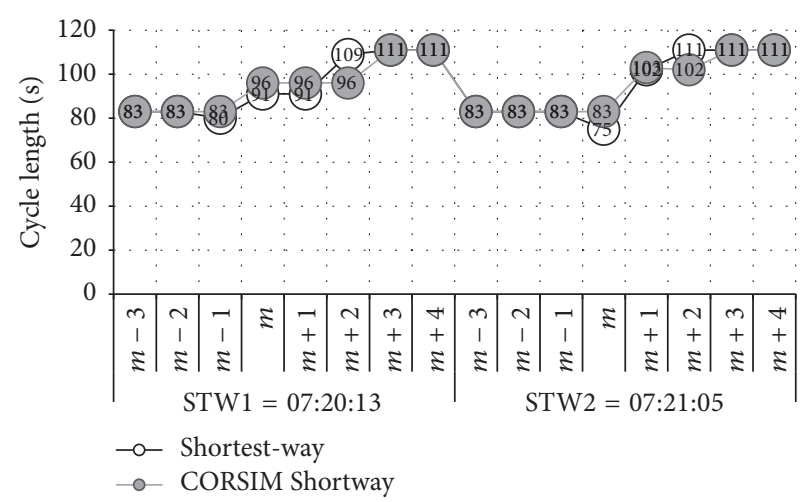

(b) Exp. $2\left(\mathrm{SR}_{m}=07: 20: 00 ; \mathrm{SR}_{m+1}=07: 21: 23\right)$

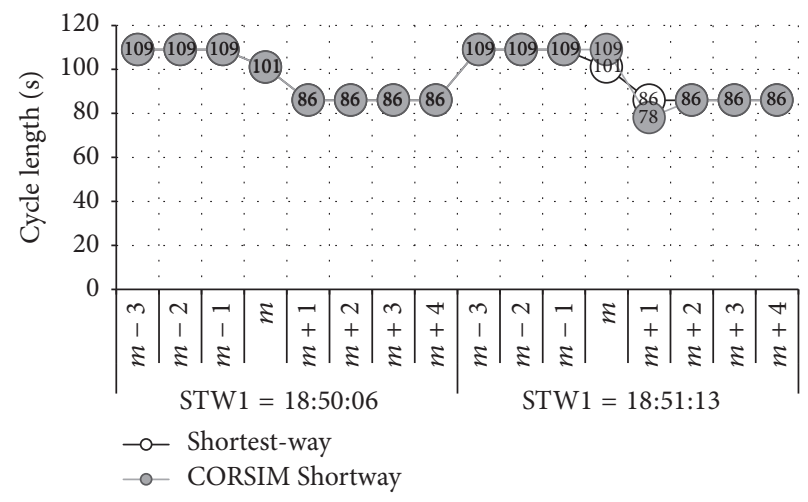

(d) Exp. $4\left(\mathrm{SR}_{m}=18: 50: 00 ; \mathrm{SR}_{m+1}=18: 51: 49\right)$

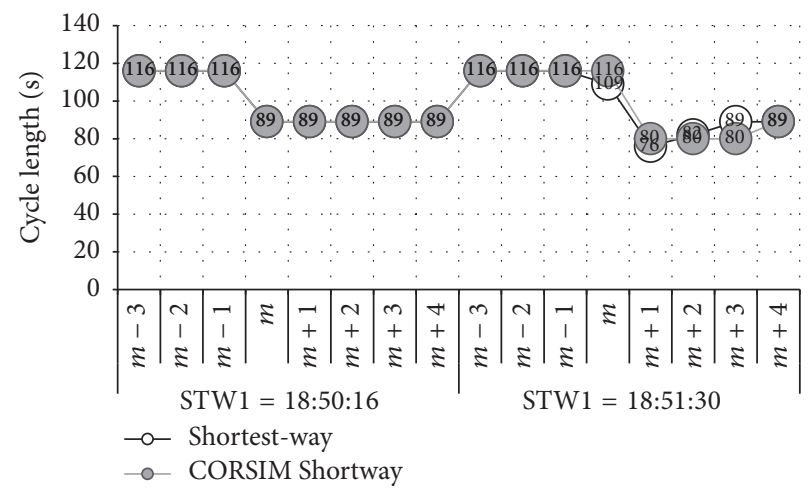

(f) $\operatorname{Exp} .6\left(\mathrm{SR}_{m}=18: 50: 00 ; \mathrm{SR}_{m+1}=18: 51: 56\right)$

Figure 5: Cycle lengths between $\mathrm{SR}_{m-3}$ and $\mathrm{SR}_{m+4}$.

\section{Conclusions and Future Studies}

Transition method is an indispensable component of pretimed or actuated coordinated signal systems. This research is motivated by the need for developing an improved empirical method that is more rapid in correcting offset and less detrimental to quality of progression.

The four fundamental insights into transition methods pave the way for signal controller vendors, practitioners, and researchers to address engineering issues related to plan transition. Shortest-way inherits the stepwise working procedure of prevailing empirical methods but is unique in some key techniques. The point within the cycle where a limited amount of adjustment is started to be made to the cycle length and splits enables Shortest-way to reduce the time spent on offset correction. The way the transition cycle length and the transition splits are calculated enables Shortest-way to reduce the offset deviations of the coordinated phases during the transition period. The numerical experimental results proved the potential advantage of Shortest-way over CORSIM Shortway. It was important to note that more benefits of using Shortest-way could be anticipated if the time to switch plans was carefully managed at the intersection level. Nevertheless, the fact that the negative impact of Shortest-way on the quality of progression could not be completely eliminated supports the judgement that quality signal 


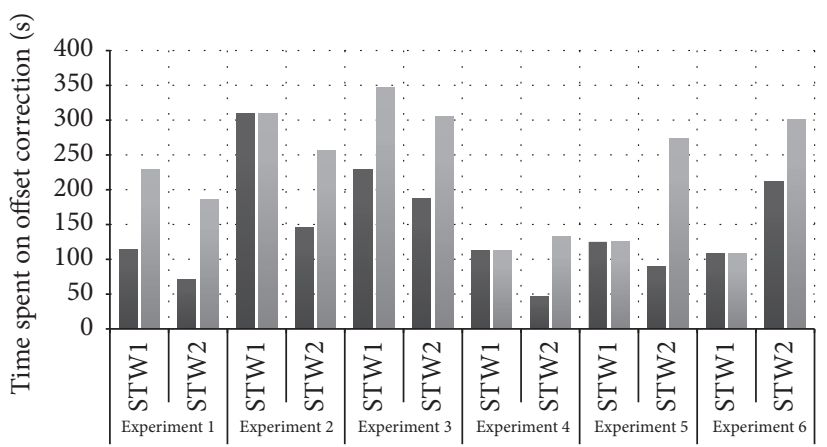

- Shortest-way

CORSIM Shortway

FIGURE 6: Time spent on offset correction.

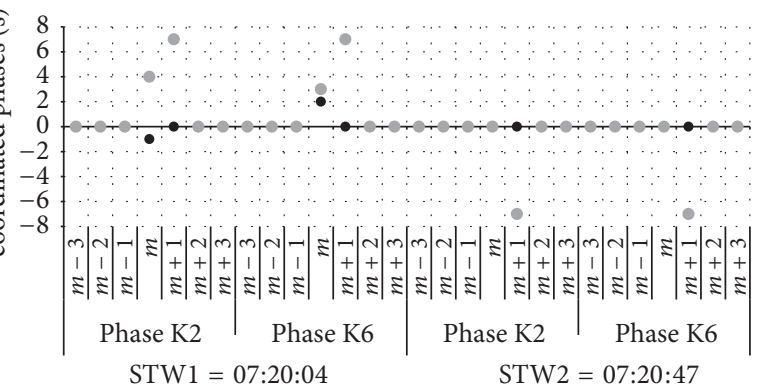

- Shortest-way

- CORSIM Shortway

(a) Exp. $1\left(\mathrm{SR}_{m}=07: 20: 00 ; \mathrm{SR}_{m+1}=07: 21: 28\right)$

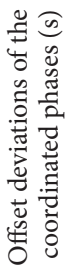

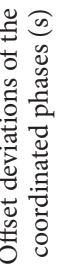

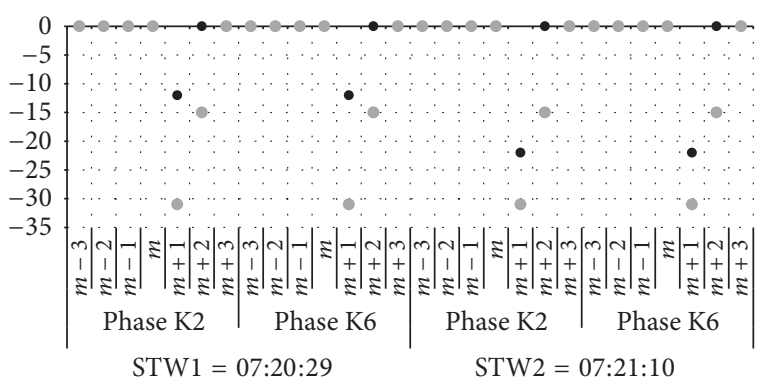

- Shortest-way

- CORSIM Shortway

(c) Exp. $3\left(\mathrm{SR}_{m}=07: 20: 00 ; \mathrm{SR}_{m+1}=07: 21: 35\right)$

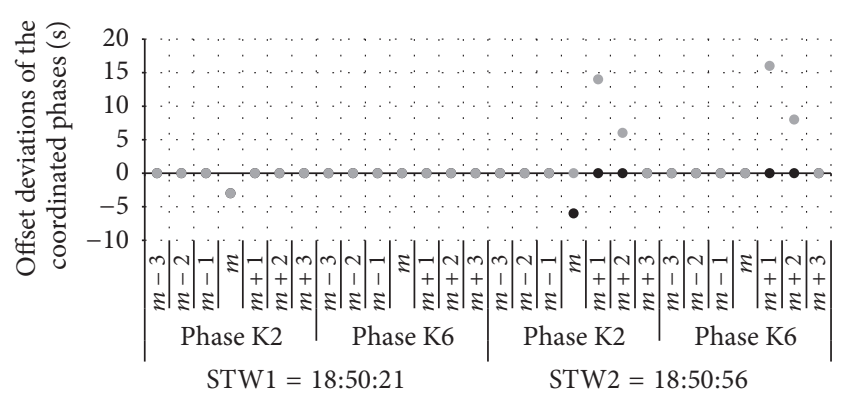

- Shortest-way

- CORSIM Shortway

(e) $\operatorname{Exp} .5\left(\mathrm{SR}_{m}=18: 50: 00 ; \mathrm{SR}_{m+1}=18: 52: 00\right)$

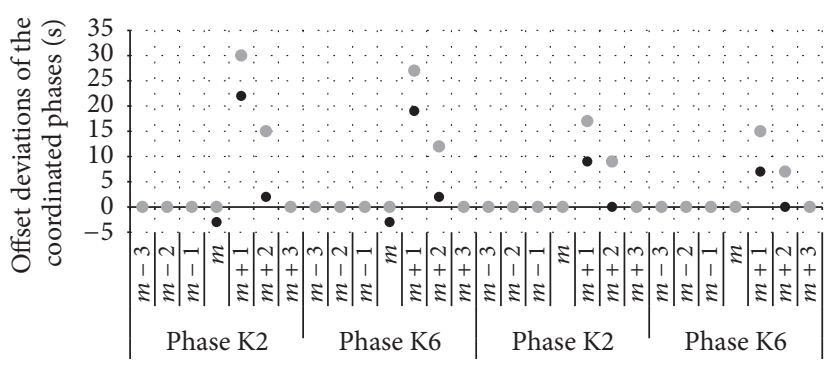

STW1 $=07: 20: 13$

- Shortest-way

- CORSIM Shortway

(b) Exp. $2\left(\mathrm{SR}_{m}=07: 20: 00 ; \mathrm{SR}_{m+1}=07: 21: 23\right)$

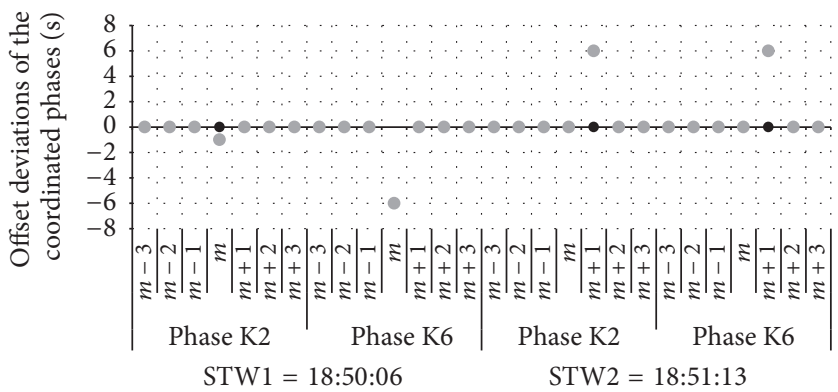

- Shortest-way

- CORSIM Shortway

(d) Exp. $4\left(\mathrm{SR}_{m}=18: 50: 00 ; \mathrm{SR}_{m+1}=18: 51: 49\right)$

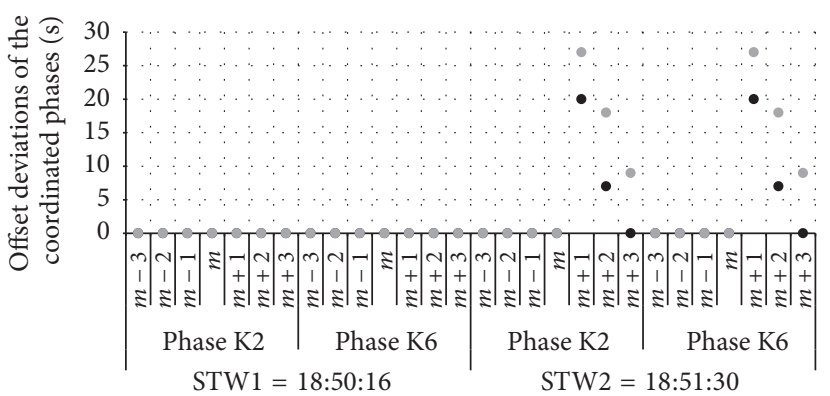

- Shortest-way

- CORSIM Shortway

(f) Exp. $6\left(\mathrm{SR}_{m}=18: 50: 00 ; \mathrm{SR}_{m+1}=18: 51: 56\right)$

FIgURE 7: Offset deviations of the coordinated phases. 
TABle 2: Old and new plans for experiments 1 to 6 .

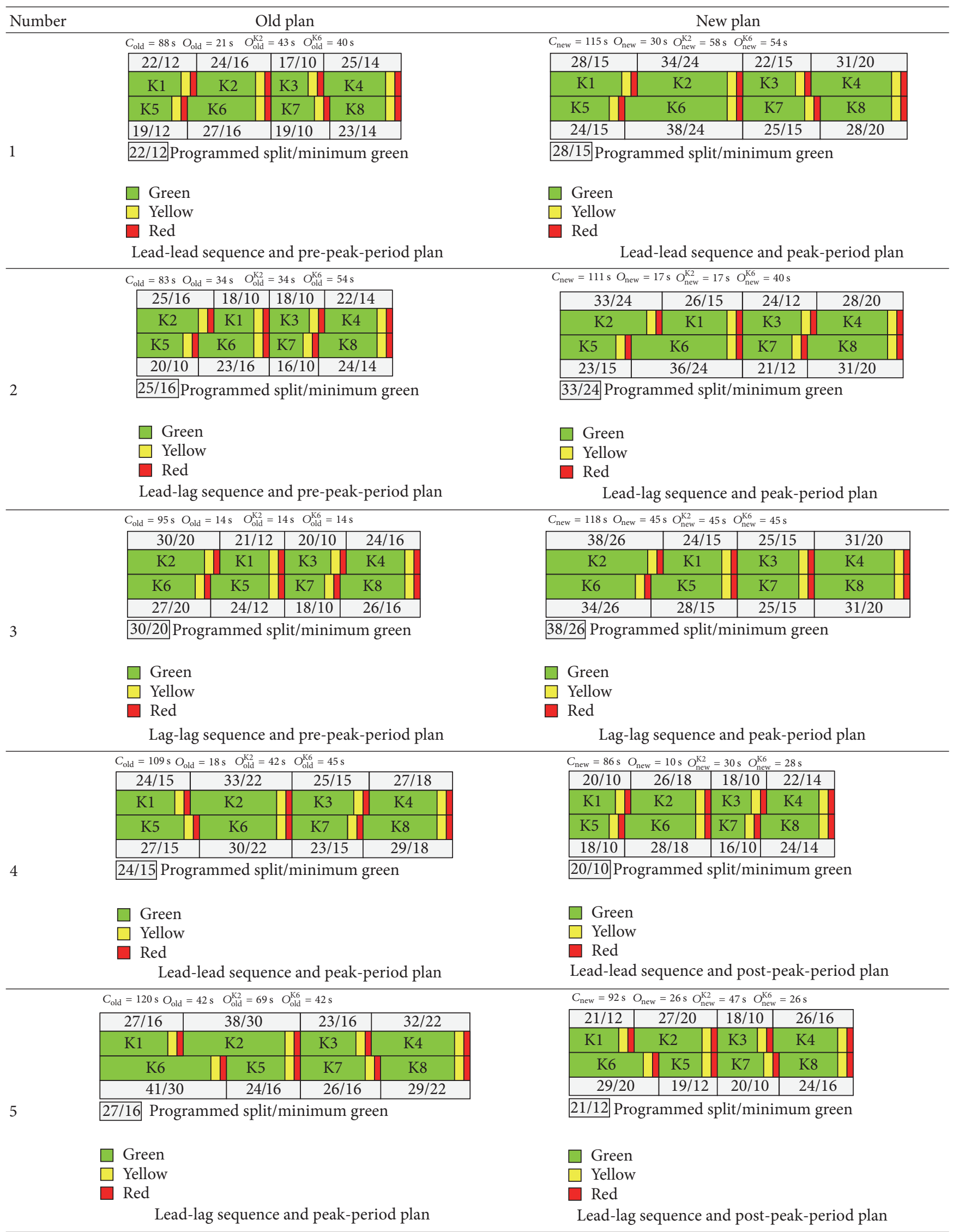


TABLE 2: Continued.

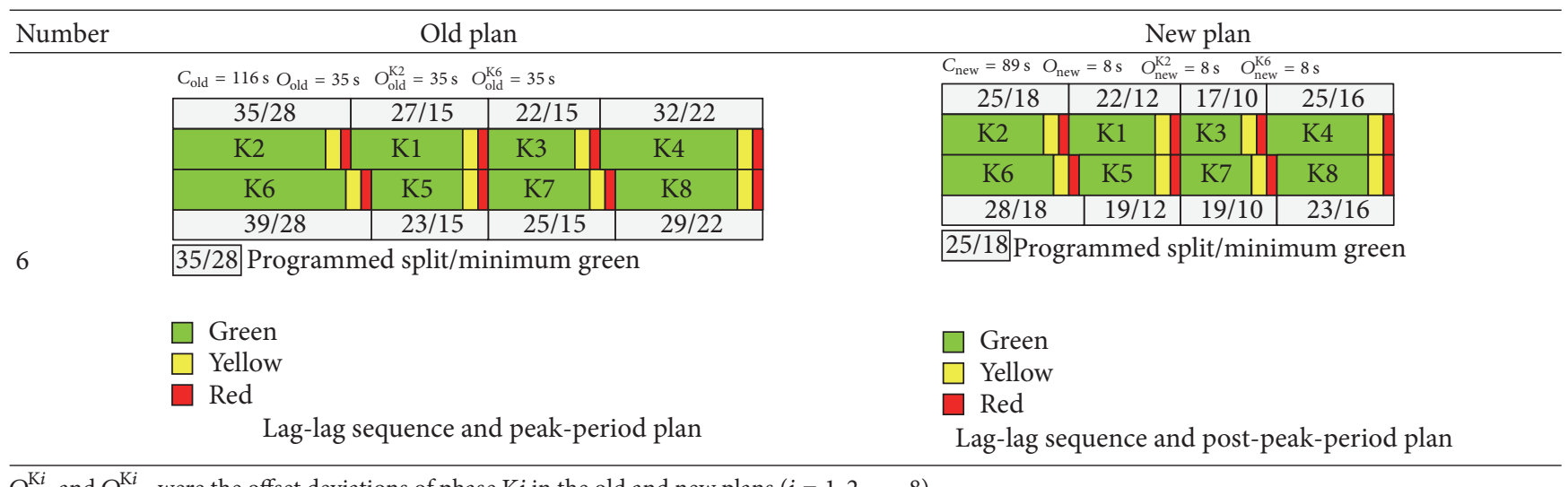

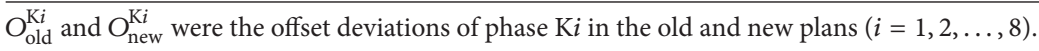

plans and appropriate times to switch plans far outweigh a transition method in affecting the systemwide performance of an arterial.

In future studies, a screening method for optimal time to switch plans will be developed for Shortest-way. Also, extensive simulation experiments will be conducted to examine the dynamic performance of Shortest-way and provide engineering guidance on implementing Shortest-way.

\section{Competing Interests}

The authors declare that they have no competing interests.

\section{Acknowledgments}

This research is a part of the project "Development and Application of an Event-Driven Bus Rapid Transit Signal Priority at Arterials," which is sponsored by the National Natural Science Foundation of China (no. 61374193).

\section{References}

[1] E. J. Nelson and D. Bullock, "Impact of emergency vehicle preemption on signalized corridor operation: an evaluation," Transportation Research Record, no. 1727, pp. 1-11, 2000.

[2] S. Shelby, D. Bullock, and D. Gettman, "Transition methods in traffic signal control," Transportation Research Record, vol. 1978, pp. 130-140, 2006.

[3] D. Cohen, L. Head, and S. G. Shelby, "Performance analysis of coordinated traffic signals during transition," Transportation Research Record, no. 2035, pp. 19-31, 2007.

[4] J. Lee and B. M. Williams, "Fundamental insight into signal plan transition methods," Journal of Transportation Engineering, vol. 137, no. 10, pp. 676-686, 2011.

[5] I. Yun, M. Best, and B. Park, "Traffic controller performance during time-of-day transition at coordinated actuated signal systems," Transportation Research Record, no. 2080, pp. 92-99, 2008.

[6] T. Pohlmann and B. Friedrich, "Traffic signal transition in coordinated meshed networks," Transportation Research Record, no. 2192, pp. 97-107, 2010.
[7] E. Lieberman and D. Wicks, "A rapid signal transition algorithm," Transportation Research Record, vol. 509, pp. 1-15, 1974.

[8] R. Mussa and M. Selekwa, "Proposed methodology of optimizing transitioning between time-of-day timing plans," Journal of Transportation Engineering, vol. 129, no. 4, pp. 392-398, 2003.

[9] J. Lee and B. M. Williams, "Development and evaluation of a constrained optimization model for traffic signal plan transition," Transportation Research Part C: Emerging Technologies, vol. 20, no. 1, pp. 185-198, 2012.

[10] R. Peñabaena-Niebles, V. Cantillo, and J. L. Moura, "Impact of transition between signal timing plans in social cost based in delay, fuel consumption and air emissions," Transportation Research Part D: Transport and Environment, vol. 41, pp. 445456, 2015.

[11] R. Peñabaena-Niebles, V. Cantillo, S. Cuentas, and J. L. Moura, "Transition between signal timing plans: a methodological and analytical overview," Transport Reviews, vol. 34, no. 3, pp. 356378, 2014.

[12] T. Urbanik, A. Tanaka, B. Lozner et al., NCHRP Report 812: Signal Timing Manual, Transportation Research Board, Washington, DC, USA, 2nd edition, 2015, timing manual, second edition.

[13] R. Akçelik and N. M. Rouphail, "Estimation of delays at traffic signals for variable demand conditions," Transportation Research Part B, vol. 27, no. 2, pp. 109-131, 1993.

[14] R. Akcelik, Research Report ARR 123: Traffic Signals: Capacity and Timing Analysis, Australian Road Research Board, Melbourne, Australia, 7th edition, 1998.

[15] H. Rakha, Y.-S. Kang, and F. Dion, "Estimating vehicle stops at undersaturated and oversaturated fixed-time signalized intersections," Transportation Research Record, no. 1776, pp. 128-137, 2001.

[16] Transportation Research Board, NCHRP Project 3-92: Highway Capacity Manual 2010, National Research Council, Washington, DC, USA, 2010.

[17] ITT Industries Inc, CORSIM User's Guide Version 6.0, Federal Highway Administration, Washington, DC, USA, 2006. 


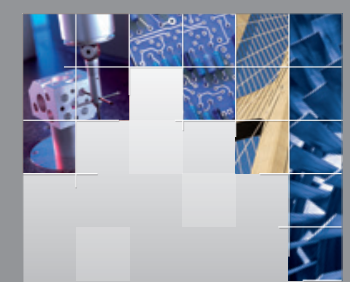

\section{Enfincering}
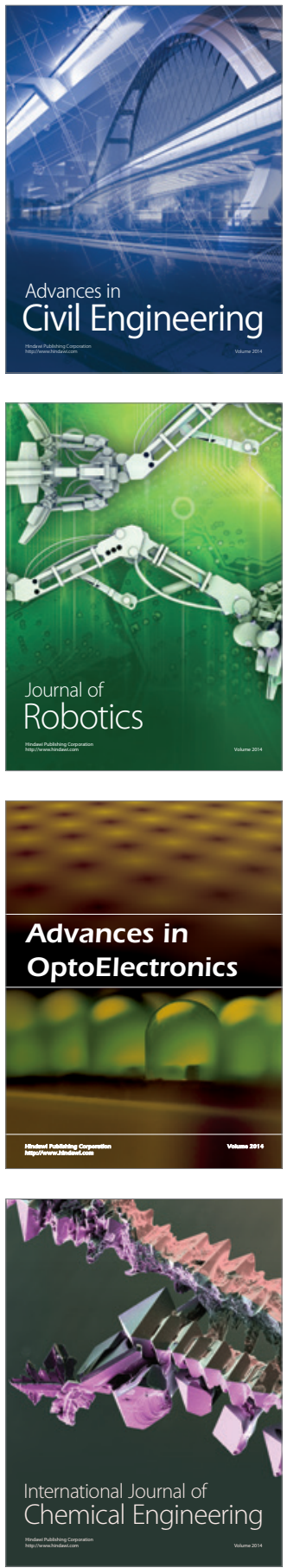

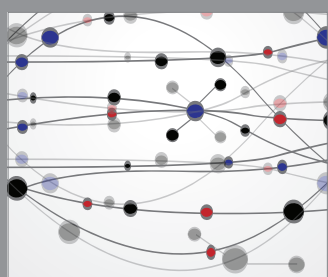

The Scientific World Journal

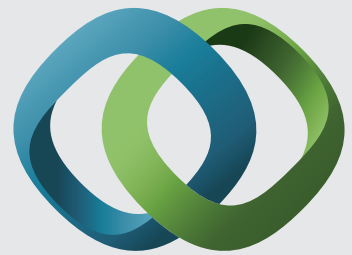

\section{Hindawi}

Submit your manuscripts at

https://www.hindawi.com
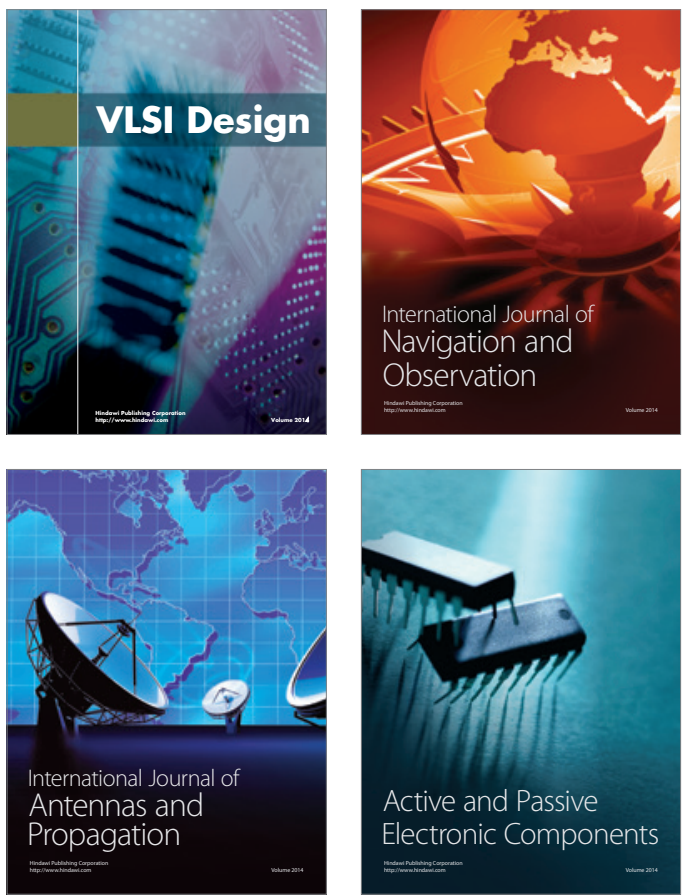
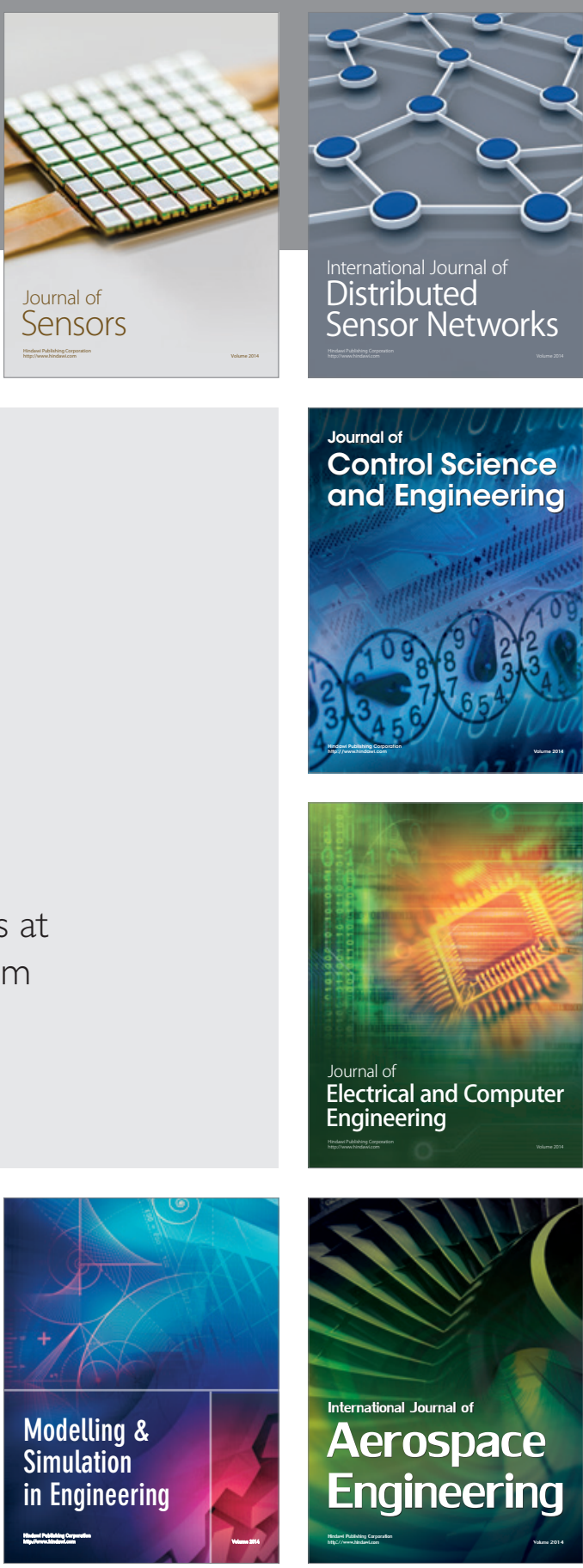

International Journal of

Distributed

Sensor Networks

$-$

Joumal of

Control Science

and Engineering
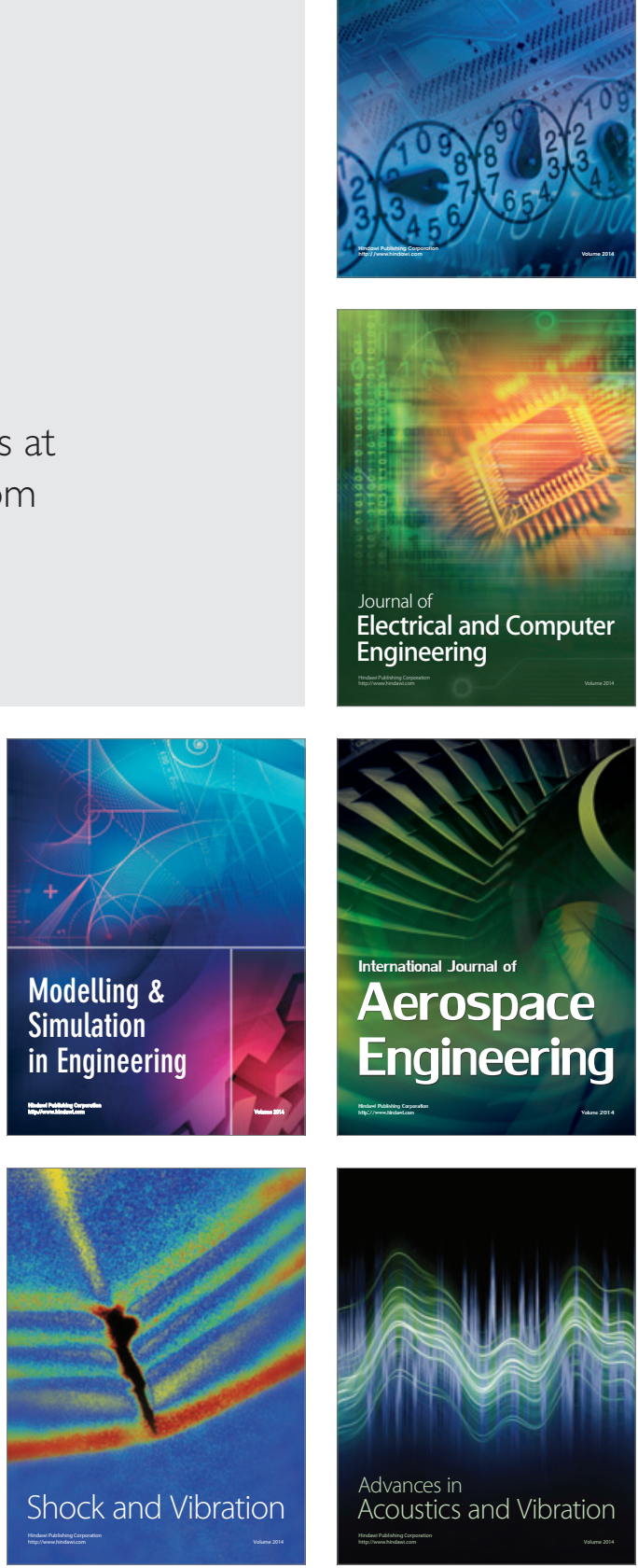